\title{
Small-scale contact angle mapping on undisturbed soil surfaces
}

\author{
Joerg Bachmann ${ }^{*}$, Marc-O. Goebel, Susanne K. Woche \\ Institute of Soil Science, Leibniz University Hannover, Herrenhäuser Str. 2, 30419 Hannover, Germany. \\ * Corresponding author. E-mail: bachmann@ifbk.uni-hannover.de
}

\begin{abstract}
Research of the last years pointed out that most soils are neither completely hydrophilic nor hydrophobic, but exhibit a subcritical level of water repellency (i.e. contact angle, $\mathrm{CA}>0^{\circ}$ and $<90^{\circ}$ ). Soil water repellency (SWR) is mainly caused by organic compounds of different origin and structure, showing the relevance of biofilms and organic coatings present at many particle surfaces. Despite the importance of SWR for hydraulic processes like preferential flow phenomena, generation of heterogeneous moisture patterns, or surface run-off generation, detailed investigations on the spatial variability of SWR at various scales have rarely been carried out. We introduce a new and easy-to-apply operation for measuring the spatial distribution of SWR using a modified sessile drop method for direct optical assessment of CA at a small scale. The specific objectives of this paper are to apply a sampling and preparation technique that preserves the original spatial arrangement of soil particles and to characterize soil wettability in terms of CA at a high spatial resolution. Results revealed that the sampling and preparation technique allows determination of CA at the millimeter scale using droplets of $1 \mu \mathrm{L}$ volume. Direct measurement on grain surfaces of the sand fraction is possible for grain sizes $>300$ $\mu \mathrm{m}$ using drop volumes down to $0.1 \mu \mathrm{L}$. Geostatistical evaluation showed that the measurement grid scale is below the range of spatial dependency for droplets of $1 \mu \mathrm{L}$ volume, but not for measurements on single grains (pure nugget effect). Results show further that the small-scale differences in wettability, especially for CA $<90^{\circ}$, cannot be detected by the conventional WDPT test. From these findings it can be concluded that the proposed technique allows the identification of small-scale variations in wettability that may promote the formation of heterogeneous flow fields and moisture patterns in soil under unsaturated conditions.
\end{abstract}

Keywords: Hydrophobicity; Sessile drop method; Soil water repellency; Water drop penetration time; Wettability.

\section{INTRODUCTION}

Soil as a porous three-phase system is characterized by a tremendously high surface area to volume ratio. Complex interactions of physical, chemical, and biological processes occur at soil particle interfaces. Along with electrostatic properties, the interfacial polar and non-polar properties control the wetting kinetics, the physical status of adsorbed water films, flocculation, adsorption of solutes and colloids, and they are also a major contributor to the rheological properties of clayey soil. If a soil is not completely wettable for water it is considered to be water repellent. Soil water repellency (SWR) is caused by low surface free energy of the soil particles resulting in a weak attraction to the liquid phase (Roy and McGill, 2002). For such soils water balls up when placed on the surface and a contact angle (CA) becomes measurable. The intrinsic CA $(\alpha)$ that forms at the three-phase (solid-liquid-gas) contact line is described by the Young equation (Young, 1805, Fig. 1):

$\cos \alpha=\frac{\gamma_{\mathrm{sg}}-\gamma_{\mathrm{sl}}}{\gamma_{\mathrm{lg}}}$,

where $\gamma_{\mathrm{sg}}, \gamma_{\mathrm{s}}$, and $\gamma_{\mathrm{gg}}\left(\mathrm{mJ} \mathrm{m}^{-2}\right)$ are the interfacial energies of the solid-gas, solid-liquid, and liquid-gas interface, respectively. A $\mathrm{CA}>0^{\circ}$ and $<90^{\circ}$ indicates reduced wettability (also termed as subcritical SWR) and a CA $>90^{\circ}$ indicates hydrophobicity.

SWR can have a huge hydraulic impact that reaches from decreased infiltration rates (Jarvis, 2007; Lamparter et al., 2010a; Moore et al., 2010; Goebel et al., 2012) to preferential flow of water through the soil profile (Ritsema and Dekker, 1996) and enhanced surface run-off (Doerr et al., 2000). It could further be shown that SWR also affects ecological pro- cesses like microbial respiration which is related to carbon turnover dynamics (Goebel et al., 2005; 2007; 2011). Generally, it has become evident during the last three decades that SWR is a common and widespread phenomenon in soils around the world (Doerr et al., 2000). Many soils under different land use and climatic conditions exhibit SWR, regardless of their texture (DeBano, 2000; Jaramillo et al., 2000). Research of recent years indicates that most soils are neither completely wettable nor hydrophobic, but exhibit a subcritical level of SWR (i.e. $\left.0^{\circ}<\mathrm{CA}<90^{\circ}\right)($ Cerda and Doerr, 2007; Goebel et al., 2008; Madsen et al., 2011). As shown by Woche et al. (2005), SWR is not restricted to the topsoil but can even occur in greater depths.

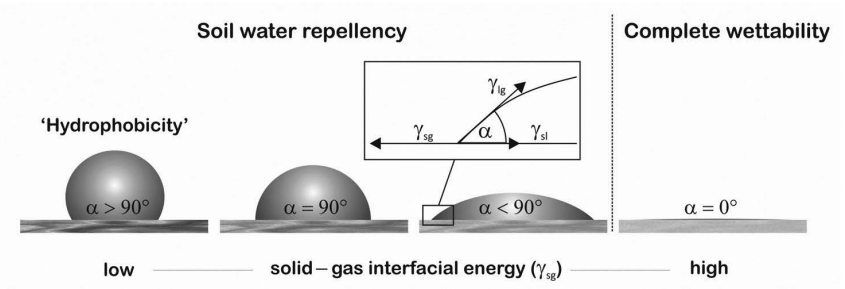

Fig. 1. Schematic showing the contact angle $(\alpha)$ and its relationship to the interfacial energies $(\gamma)$ of the three-phase (solid-liquid-gas) system (modified after Goebel et al., 2011).

SWR is mainly caused by organic compounds of different origin and structure (Doerr et al., 2000), which illustrates the relevance of biofilms and organic coatings present at many particle surfaces (Hallett and Young, 1999). The wettability of soil particles generally increases with the charge density and fraction of polar groups on the surfaces (Bachmann et al., 2001). Sorption of organic matter with non-polar functional 
groups promotes non-wettable surfaces (Ellerbrock et al., 2005), and long-chain amphiphilic organic compounds produced by a range of biota can induce hydrophobicity in soil (Capriel et al., 1995). When wetted, these compounds are usually hydrophilic, but drying can cause bonding of hydrophilic (polar) ends of amphiphilic molecules to each other or to particle surfaces, resulting in exposed hydrophobic (non-polar) functional groups towards the pore space (Hallett et al., 2010). Also root mucilage (Moradi et al., 2012), plant leaves, bacterial exudates as well as mycelia and exudates produced by fungi have been associated with the development of SWR in many studies (Doerr et al., 2000).

SWR has been identified, especially in the past two decades, as an important physical factor promoting hydraulic heterogeneity in soil. Macroscopically, the moisture content of terrestrial soils varies mostly between field capacity and permanent wilting point, with a typical size of water menisci at field capacity being approximately in the order of $\mu \mathrm{m}$. Using confocal laser scanning microscopy, Muehl et al. (2012) have shown that desaturation of a porous medium is accompanied by changes in the liquid-gas interfacial configurations. They reported that even subcritical levels of SWR may lead to a decrease in the water-wetted area and the connectivity of the water phase. As discussed by Goebel et al. (2011), the fragmentation of the liquid phase in the soil matrix can have important effects on the living conditions of microorganisms as it leads to a reduction of water flow and may reduce the diffusion of enzymes and nutrients (Or et al., 2007). Hence, increased heterogeneity of the organic phase in soil determines the relationship between the geochemistry of pore surfaces and the corresponding living conditions for microorganisms or plants in a complex manner. Since organic matter may either cover the mineral grains as thin coatings or exist as adsorbed nano-sized microaggregates (Bachmann et al., 2008), a high spatial variability of SWR can be expected at small scales (Nunan et al., 2002). However, despite the importance of interfacial phenomena in soils, detailed investigations considering the spatial variability of SWR at small scales with adequately sensitive methods have rarely been carried out.

At a larger (core sample) scale it has also been shown that the extent and spatial arrangement of microbial biofilms affect soil water retention, saturated and unsaturated hydraulic conductivity as well as the transport processes of colloids and solutes. Lamparter et al. (2010a) recently suggested microscopic blocking of pores to be relevant for water flow under certain unsaturated moisture conditions. In-situ infiltration rates of water and ethanol (which can be considered as a completely wetting liquid) were measured on sandy soils with different degrees of SWR using tension disc infiltrometry. Their experiments showed that infiltration of ethanol was up to two orders of magnitude larger compared with water, reflecting the reduced wettability relevant even under field moist conditions. It is interesting to note that the water drop penetration time (WDPT) test as a common field test for SWR was not able to detect distinct SWR for these sites under the given moisture conditions. Corresponding findings for dry soils with a wide range of textures were already described by Bachmann et al. (2003) (Fig. 2).

The CA, as a measure for the wetting properties, is usually determined on a small amount of dry and homogenized material. However, recently Ramirez-Flores et al. (2008) showed that homogenizing soil material (e.g. crushing of aggregates) can affect the CA. They explained their findings by the different spatial location of water repellent organic matter within aggregates. In conclusion, the size of the sample that is homogenized prior to the CA measurement may affect the results, depending on the ratio between aggregate surface area and interior area.

The specific objectives of this paper are (i) to apply a sampling and preparation technique that preserves the original spatial arrangement of the grains, (ii) to characterize soil wettability in terms of CA at high spatial resolution, and (iii) to compare the measured small-scale CA with those determined with the conventional approach using homogenized material.

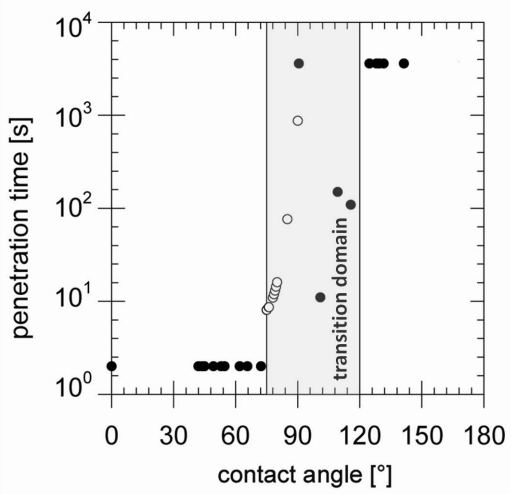

Fig. 2. Contact angle vs. penetration time (WDPT) of water droplets (50 $\mu \mathrm{L}$ drop volume) (modified after Bachmann et al., 2003).

\section{MATERIAL AND METHODS Soil material}

The study was conducted with soil from the site 'Elze', located in the Fuhrberger Feld $30 \mathrm{~km}$ NE of Hannover, Germany. The mean annual temperature of this area is $8.9^{\circ} \mathrm{C}$ and the mean annual precipitation is $680 \mathrm{~mm}$. The area is characterized by a sandy soil texture (clay content $<2.5 \%$ ) and is vegetated mainly by pine trees (Pinus sylvestris L.). The soil type is a relictic Gleyic Podzol (FAO) since the water table of this area has been lowered from approximately $1.2 \mathrm{~m}$ below ground to a level $>3$ $\mathrm{m}$. Some basic soil data are given in Table 1 .

The soil profile and the sampling positions of the core samples are shown in Fig. 3. The samples were taken horizontally with two steel cores (diameter $8.48 \mathrm{~cm}$, height $6 \mathrm{~cm}$ ) fixed on each other. In the laboratory the cores were separated with a thin steel wire (diameter $0.15 \mathrm{~mm}$ ) resulting, after removal of excess material, in two fresh surfaces. The cores were then dried at $40^{\circ} \mathrm{C}$ until constant weight was reached.

\section{Contact angle measurements}

Determination of CA with the sessile drop method usually involves a thin layer of homogenized soil material (ideally a one-grain-layer to avoid a capillary system) fixed on a glass slide with double-sided adhesive tape (Bachmann et al., 2003). In order to evaluate the small-scale variability of CA for the grains in their original spatial arrangement we improved the sampling technique introduced by Lamparter et al. (2010b). For this, double-sided adhesive tape was fixed to a flexible tissue and then pressed gently on the core sample surface. Using a flexible tissue allowed us to achieve a nearly complete surface coverage. Additionally, from the same regions material was taken and homogenized to be characterized with the conventional method as described in Bachmann et al. (2003).

The CA was measured with water drops on straight line grids. The minimum width of the sample grid was found to depend on the wettability of the sample, which determines the extent of water spreading on the sample surface. Additionally, 
A

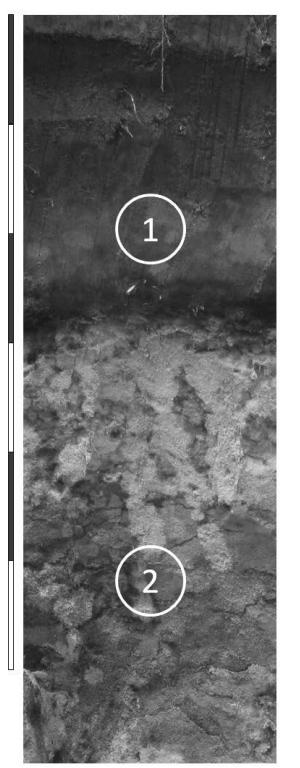

B

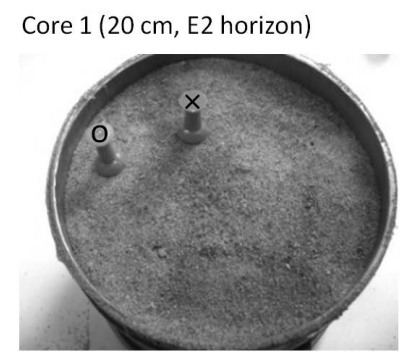

Core $2(50 \mathrm{~cm}, \mathrm{Bh}(-\mathrm{C})$ horizon)

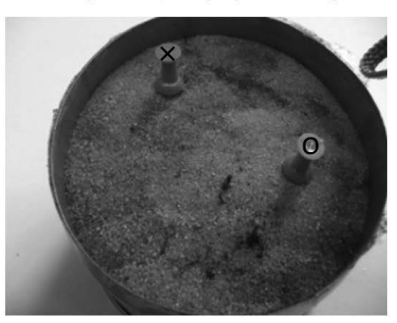

Fig. 3. Soil profile of the site 'Elze' (A); the white circles show the positions where the core samples were taken. Upper surfaces of the core samples (B); the pins indicate the domains where the material for the conventional contact angle measurements was extracted $(\times$ $=$ dark domain, $\mathrm{o}=$ bright domain) .

the appropriate drop size depends on the texture. For the regular CA mapping a resolution of $2 \times 3 \mathrm{~mm}(1 \mu \mathrm{L}$ drop volume, Sample 1) and for the CA determination directly on the quartz grains a resolution of $1 \times 1 \mathrm{~mm}(0.1 \mu \mathrm{L}$ drop volume, Sample 2) was found to be appropriate. The drop size in relation to the grain size is indicated in Fig. 4.

The CA was determined with a CCD equipped contact angle microscope (OCA 15, DataPhysics, Filderstadt, Germany). The placement of a drop of water was recorded by a video camera allowing the evaluation of CA at any time after placing using the software SCA20 (DataPhysics, Filderstadt, Germany). The first frame, approximately $0.03 \mathrm{~s}$ after a stable (vibration free) drop shape was observed, was taken as the initial CA. For the conventional measurements made on disturbed and homogenized material (using a drop volume of $3 \mu \mathrm{L}$ ), the CA was additionally analyzed after 1,5 , and $10 \mathrm{~s}$. For drops covering several grains a horizontal baseline was defined, while for drops on single grains a curved baseline was used that fitted the grain shape (Fig. 4). The measured CA were analyzed by conventional statistics and geostatistical methods.

Complementary to the CA investigations, WDPT measurements were made with six droplets per sample $(50 \mu \mathrm{L}$ drop volume) which were placed directly on the prepared soil core surface. For each droplet the time that elapsed until the water had completely infiltrated was determined and the median was calculated by averaging the times of the two droplets with intermediate infiltration times.

Table 1. Basic chemical and physical properties of the profile 'Elze'.

\begin{tabular}{|c|c|c|c|c|c|c|c|c|c|c|c|c|}
\hline \multirow[t]{2}{*}{$\begin{array}{l}\text { Hori- } \\
\text { zon }\end{array}$} & \multirow[t]{2}{*}{$\begin{array}{l}\text { Depth } \\
(\mathrm{cm})\end{array}$} & \multicolumn{3}{|c|}{$\begin{array}{c}\text { Texture } \\
\text { (\% by mass) }\end{array}$} & \multirow[t]{2}{*}{$\begin{array}{c}\mathrm{BD} \\
\left(\mathrm{g} \mathrm{cm}^{-3}\right)\end{array}$} & \multicolumn{2}{|c|}{$\mathrm{pH}$} & \multirow[t]{2}{*}{$\begin{array}{c}\text { SOC } \\
\text { (\% by mass) }\end{array}$} & \multirow[t]{2}{*}{$\begin{array}{c}\text { SON } \\
\text { (\% by mass })\end{array}$} & \multicolumn{2}{|c|}{$\begin{array}{c}\text { CEC } \\
\left(\mathrm{mmol}_{\mathrm{c}}\left[\mathrm{kg} \mathrm{soil}{ }^{-1}\right]\right)\end{array}$} & \multirow[t]{2}{*}{$\begin{array}{c}\mathrm{BS} \\
\text { (\% of } \mathrm{CEC}_{\text {eff }} \text { ) }\end{array}$} \\
\hline & & sand & silt & clay & & $\mathrm{H}_{2} \mathrm{O}$ & $\mathrm{CaCl}_{2}$ & & & $\mathrm{CEC}_{\text {pot }}$ & $\mathrm{CEC}_{\text {eff }}$ & \\
\hline $\mathrm{Ah}$ & $0-10$ & 92.8 & 5.6 & 1.6 & 1.1 & 4.9 & 4.0 & 2.30 & 0.057 & 102 & 37 & 8 \\
\hline E1 & $10-18$ & 96.1 & 3.5 & 0.4 & 1.1 & 4.5 & 3.5 & 1.40 & 0.019 & 44 & 21 & 14 \\
\hline E2 & $18-27$ & 95.1 & 4.3 & 0.6 & 1.5 & 4.6 & 3.7 & 0.68 & 0.013 & 27 & 13 & 7 \\
\hline $\mathrm{Bh}$ & $27-30$ & 93.8 & 3.8 & 2.5 & 1.2 & 4.2 & 3.5 & 3.12 & 0.079 & 195 & 77 & 2 \\
\hline Bs & $30-36$ & 92.4 & 5.1 & 2.5 & 1.2 & 4.7 & 4.3 & 2.00 & 0.042 & 182 & 45 & 14 \\
\hline Bhs & $36-46$ & 95.0 & 4.4 & 0.6 & & 4.9 & 4.7 & 0.55 & 0.018 & 56 & 10 & 14 \\
\hline $\mathrm{Bh}(-\mathrm{C})$ & $46-75$ & 98.5 & 1.2 & 0.3 & 15.16 & 4.9 & 4.7 & 0.15 & 0.006 & 19 & 6 & 24 \\
\hline Bh-C & $75-120$ & 99.5 & 0.3 & 0.2 & $1.5-1.6$ & 5.0 & 4.7 & 0.10 & 0.004 & 14 & 4 & 12 \\
\hline $\mathrm{C}$ & $>120$ & 99.6 & 0.4 & 0.1 & & 4.9 & 4.7 & 0.07 & 0.004 & 9 & 3 & 16 \\
\hline
\end{tabular}

$\mathrm{BD}$ is bulk density, $\mathrm{SOC}$ is soil organic carbon, $\mathrm{SON}$ is soil organic nitrogen, $\mathrm{CEC}_{\mathrm{pot}}$ and $\mathrm{CEC}_{\mathrm{eff}}$ are the potential and effective cation exchange capacity, respectively, BS is base saturation.

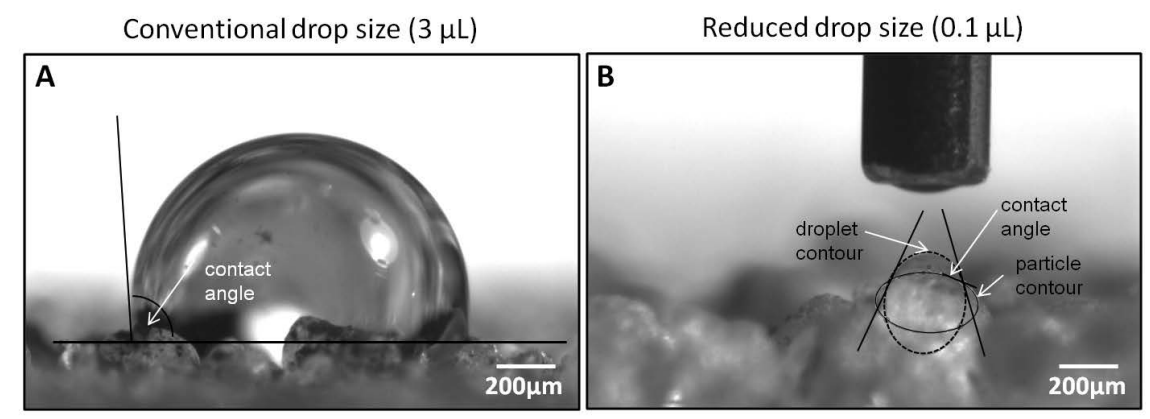

Fig. 4. Comparison of drop size used for the conventional contact angle measurements on a layer of grains ( $3 \mu \mathrm{L}$ drop volume) (A) and for contact angle measurements made on single grains $(0.1 \mu \mathrm{L}$ drop volume) (B). The baseline for conventional measurements is horizontal, for measurements on single grains the approximated contour line of the particle.

\section{RESULTS AND DISCUSSION}

Fig. 5 shows a sample from the E2 horizon $(20 \mathrm{~cm}$ depth $)$ with the original arrangement of grains (Sample 1). The uneven coloring with brighter and darker domains indicates an inho- mogeneous distribution of organic matter. Small-scale CA analysis gives a range of CA from $47^{\circ}$ to $140^{\circ}$ with larger CA roughly found in the darker domains (Fig. 6A). Geostatistical evaluation of the small-scale CA data shows that a grid width of $2 \times 3 \mathrm{~mm}$ is small enough to detect a range which defines the 
distance of spatial dependency (Fig. 6B). Statistical analysis of the data $(n=216)$ indicates a normal distribution with the mean CA $\left(82.4^{\circ}\right)$ close to the median $\left(80.8^{\circ}\right.$; Fig. 7$)$. The conventional CA determination with homogenized material (Table 2) reveals comparable $\mathrm{CA}$ for the brighter $\left(84.4^{\circ}\right)$ and darker domains $\left(86.6^{\circ}\right)$ that are quite close to the mean found with the small-scale CA analysis. Interestingly, the WDPT test (Table 2) at least indicates a difference between the brighter (WDPT $<5$ $\mathrm{s})$ and the darker domains (WDPT $=8 \mathrm{~s}$ ).

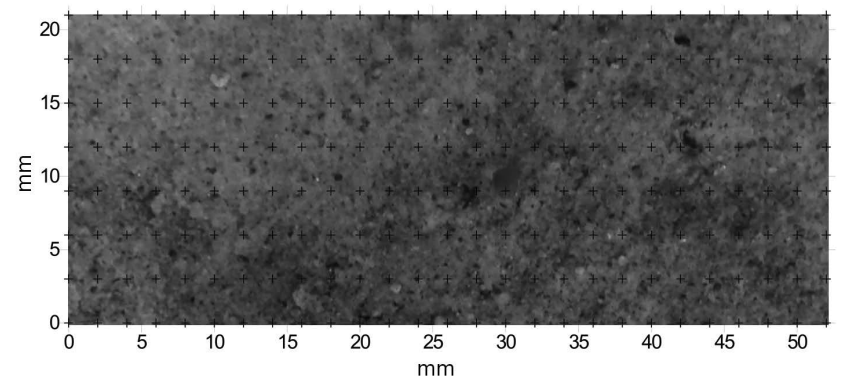

Fig. 5. Photograph showing the prepared sample surface where almost complete surface coverage could be achieved (Sample 1). The crosshairs indicate the measurement grid.
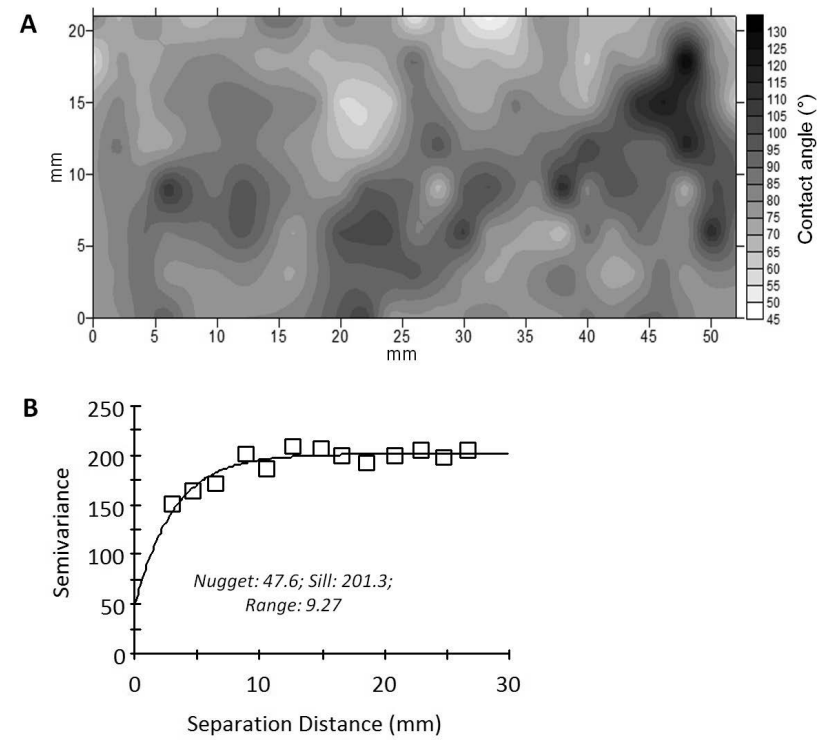

Fig. 6. Contour map (A) and semivariogram (B) of the contact angle mapping using a drop volume of $1 \mu \mathrm{L}$ (Sample 1). Number of grid points for the contact angle measurements $n=216$; grid distance for $\mathrm{x}$-axis $=2 \mathrm{~mm}$, for $\mathrm{y}$-axis $=3 \mathrm{~mm}$.

Our results are in contrast to Hallett et al. (2004), who could not find a small-scale spatial dependence of SWR using sorptivity measurements on the millimeter-scale. This may probably be explained by the different factors determining SWR at different spatial scales, for instance, soil type, texture, structure, chemical milieu, type of vegetation, and land-use practice.

The results of our small-scale CA analysis, with CA between $47^{\circ}$ and $140^{\circ}$, show that the new sampling technique and the use of small drops are able to resolve differences in the wetting properties at a high resolution (millimeter-scale). This smallscale spatial variability of SWR is important as it can induce very high levels of spatial variability in water transport (Hallett et al., 2004). For instance, Ritsema and Dekker (1996) used the WDPT test to investigate the spatial distribution of wettability in sandy soils with a very high level of SWR and found a good correlation between SWR and the tendency for preferential flow. However, the often applied WDPT test can only be used to differentiate the degree of SWR for strongly water repellent (i.e. hydrophobic) soils, since penetration times just indicate roughly the period when the CA decreases from a unknown value $>90^{\circ}$ down to CA around $90^{\circ}$ or less (compare Fig. 2). Consequently, a large area of the contour map shown in Fig. 6A with CA smaller than approximately $90^{\circ}$ would not be differentiated by WDPT. Thus, SWR in the so-called subcritical domain (i.e. for $0^{\circ}<\mathrm{CA}<90^{\circ}$ ) cannot be reliably determined or differentiated with the WDPT test. This is confirmed by the data shown in Table. 2. However, even subcritical SWR might be important for physical processes in soil (e.g. Lamparter et al., 2010). Hallett et al. (2004) made a first attempt to detect the spatial pattern of subcritical SWR by using sorptivity measurements with water and ethanol at a small scale. With this technique, introduced by Tillman et al. (1989), even subcritical SWR can be detected. However, this method is expected to be more time consuming.

An even higher resolution of wetting properties was achieved by determination of CA on single quartz grains (Fig. 8) using a sample consisting of both a brighter and darker domain (Sample 2) extracted from the $\mathrm{Bh}(-\mathrm{C})$ horizon $(50 \mathrm{~cm}$ depth). In this case, even with a smaller grid size of $1 \mathrm{~mm}$, we could not find a range of spatial dependency of CA. Conventional CA determination with homogenized material indicated greater CA for the brighter $\left(81.6^{\circ}\right)$ and smaller CA $\left(68^{\circ}\right)$ for the darker domain which was reflected in much greater WDPT of $>$ $>400 \mathrm{~s}$ for the brighter than for the darker domain (WDPT $<5$ s) (Table 2). It was also observed that the bright domain is characterized by relatively small changes in CA with time (Table 2), which indicates the high persistency in this horizon. $\mathrm{CA}$ analysis on single quartz grains gave a somewhat different picture. Here the mean CA was greater for the darker domain ( $37.7^{\circ}$ compared with $21.8^{\circ}$ ) and both mean CA were distinctly smaller than those obtained using the conventional approach. The range of CA between $5^{\circ}$ and around $80^{\circ}$ with most CA around $30^{\circ}$ for the bright and most around $60^{\circ}$ for the dark domain did not agree with the macroscopic observations.

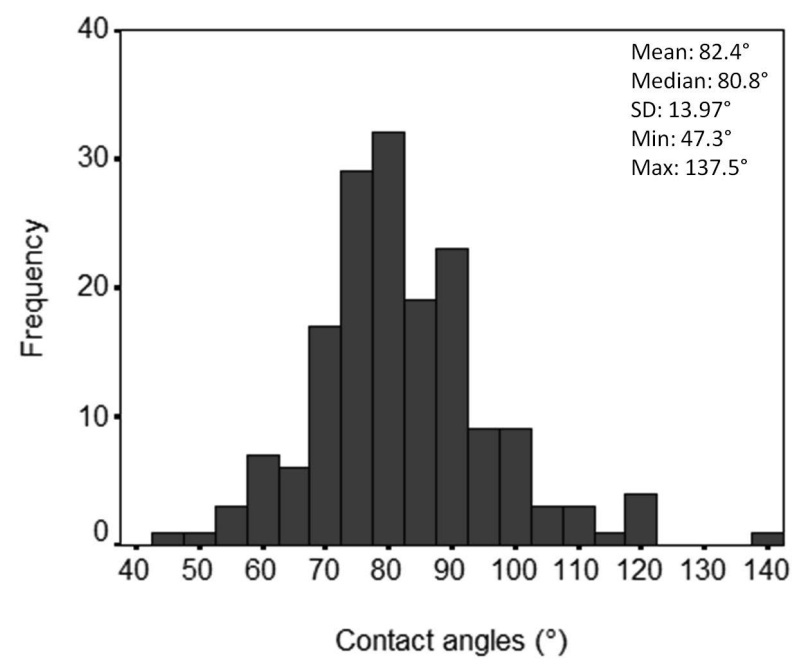

Fig. 7. Histogram of the contact angles measured on Sample 1.

These results suggest that small hydrophobic spots which create a chemically composite surface at the scale of an individual grain apparently determine the CA of larger droplets as indicated by the data in Table. 2. This observation fits with the more general observation that sessile drops do not represent 
Small-scale contact angle mapping on undisturbed soil surfaces

Table 2. Contact angles measured on homogenized material using the conventional approach ( $3 \mu \mathrm{L}$ drop volume) and water drop penetration times (WDPT).

\begin{tabular}{lcccccc}
\hline Soil horizon & $\begin{array}{c}\text { Depth } \\
(\mathrm{cm})\end{array}$ & $\begin{array}{c}\text { CA after 0.03 s } \\
\left({ }^{\circ}\right)\end{array}$ & $\begin{array}{c}\text { CA after 1 s } \\
\left({ }^{\circ}\right)\end{array}$ & $\begin{array}{c}\text { CA after 5 s } \\
\left({ }^{\circ}\right)\end{array}$ & $\begin{array}{c}\text { CA after 10 s }^{\circ} \\
\left({ }^{\circ}\right)\end{array}$ & $\begin{array}{c}\text { WDPT }^{\#} \\
(\mathrm{~s})\end{array}$ \\
\hline E2 (bright) & 20 & $84.4 \pm 10.1$ & $74.3 \pm 11.8$ & $58.5 \pm 9.7$ & $49.9 \pm 5.8$ & $<5$ \\
E2 (dark) & 20 & $86.6 \pm 7.3$ & $77.8 \pm 2.4$ & $68.9 \pm 9.8$ & $62.4 \pm 6.9$ & 8 \\
Bh & 32 & $68.9 \pm 12.5$ & $57.8 \pm 18.8$ & $46.2 \pm 22.8$ & $41.6 \pm 23.5$ & $<5$ \\
Bs & 35 & $96.9 \pm 5.7$ & $76.5 \pm 9.2$ & $67.1 \pm 9.8$ & $57.9 \pm 4.2$ & $<5$ \\
Bhs (bright) & 40 & $62.4 \pm 7.3$ & $58.9 \pm 6.5$ & $56.7 \pm 8.2$ & $56.4 \pm 8.0$ & $<5$ \\
Bhs (dark) & 40 & $82.0 \pm 13.0$ & $80.0 \pm 13.6$ & $78.1 \pm 14.2$ & $76.0 \pm 13.1$ & $<5$ \\
Bh(-C) (bright) & 50 & $81.6 \pm 11.8$ & $78.5 \pm 13.7$ & $77.8 \pm 16.4$ & $76.8 \pm 16.4$ & 437 \\
Bh(-C) (dark) & 50 & $68.0 \pm 4.4$ & $65.8 \pm 8.0$ & $66.0 \pm 11.3$ & $60.6 \pm 10.3$ & $<5$ \\
\hline
\end{tabular}

\#median of six droplets $(\mathrm{V}=50 \mu \mathrm{L})$.

equilibrium $\mathrm{CA}$ but are, to some extent, closer to the dynamic advancing type (Adamson, 1990). These are more affected by hydrophobic spots compared with equilibrium or receding angles. In case of a droplet placed on a surface it is apparent that from the moment of the first contact between liquid and solid, a liquid front moves to increase the contact area of the solid-liquid interface horizontally and vertically (filling pore entrances) until the remaining liquid forms a spherical shape and the final size is achieved.

A

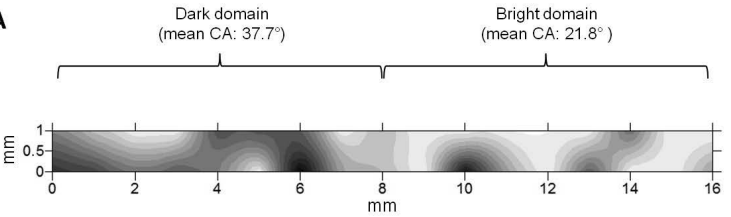

B

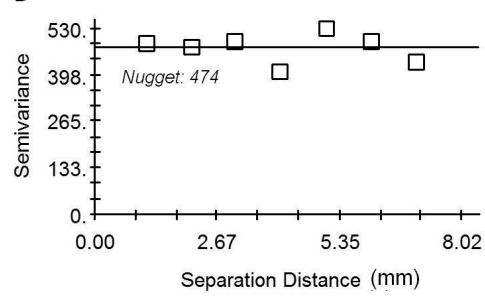

Fig. 8. Contour map (A), and semivariogram (B) of the contact angles measured on Sample $2(\mathrm{n}=32$, grid distance $1 \mathrm{~mm}, 16$ data points in $\mathrm{x}$ and 2 data points in $\mathrm{y}$ direction). Contact angles were measured on single grains using a drop volume of $0.1 \mu \mathrm{L}$.

\section{CONCLUSIONS}

We have presented an easy-to-apply method to determine the small-scale spatial distribution of SWR using a modified sample preparation technique for the sessile drop method. For a soil profile with a macroscopic moderate to high degree of SWR we could show that the sampling and preparation technique is operable in different modes yielding different results. For drops with a volume of $1 \mu \mathrm{L}, \mathrm{CA}$ measurement at a grid size between 2 and $3 \mathrm{~mm}$ is possible. The measurement scale, in this case, was found to be below the range of spatial variation of CA. A comparison between CA determined with the conventional approach on homogenized material (using a drop volume of $3 \mu \mathrm{L}$ ) and small-scale CA indicates a good agreement between the average CA. Determination of CA at the small scale allows detection of the distribution of wetting prop- erties at high spatial resolution within a small area; in this case revealing a considerable range. Application of smaller droplets $(0.1 \mu \mathrm{L})$ allows CA determination directly on individual quartz particles with a diameter $>300 \mu \mathrm{m}$. Comparison of these smallscale CA with those determined using the conventional approach indicate the important influence of small hydrophobic spots in increasing the CA determined at larger scales using a 30 times larger drop volume. In both cases the variations in wettability detected by CA cannot be resolved by the conventional WDPT test.

We conclude that the proposed method is able to identify variations in the wetting properties at the small scale that may promote the formation of inhomogeneous moisture and flow patterns in undisturbed soil under unsaturated conditions. Knowledge about the spatial distribution of SWR at the small scale may help to improve the understanding of water and solute transport in hydrophobic and subcritically water repellent soils and to elucidate important links between physical heterogeneity at the millimeter-scale caused by surface wetting properties and biological responses like root-soil interactions or spatial patterns of microorganisms in soil. Thus, enhancing the resolution of CA measurements down to the millimeter- or individual grain scale surely will help to better understand the relevance of SWR patterns for hydraulic, biological, and chemical processes.

Acknowledgement. Financial support by The German Research Foundation (DFG, SPP 1315 Biogeochemical Interfaces in Soil, BA1359/9-2) is greatly appreciated. We greatly thank Prof. Jürgen Böttcher for the analytical data of the soil profile 'Elze'.

\section{REFERENCES}

Adamson, A.W., 1990. Physical Chemistry of Surfaces (5 $5^{\text {th }}$ ed.), John Wiley and Sons, New York.

Bachmann, J., Guggenberger, G., Baumgartl, T., Ellerbrock, R.H., Urbanek, E., Goebel, M.O., Kaiser, K., Horn, R., Fischer, W.R., 2008. Physical carbon-sequestration mechanisms under special consideration of soil wettability. J. Plant Nutr. Soil Sci., 171, 14-26.

Bachmann, J., Woche, S.K., Goebel, M.O., Fischer, W.R., 2001. Contact angle and surface charge of wettable and hydrophobic silt particles. J. Soil Sci. Plant Nutr., 1, 26-33.

Bachmann, J., Woche, S.K., Goebel, M.O., Kirkham, M.B., Horton, R., 2003. Extended methodology for determining wetting properties of porous media. Water Resour. Res., 39, 1353-1366.

Capriel, P., Beck, T., Borchert, H., Gronholz, J., Zachmann, G., 1995. Hydrophobicity of the organic matter in arable soils. Soil Biol. Biochem., 27, 1453-1458. 
Cerda, A., Doerr, S.H., 2007. Soil wettability, runoff and erodibility of major dry-Mediterranean land use types on calcareous soils. Hydrol. Process., 21, 2325-2336.

DeBano, L.F., 2000. Water repellency in soils: a historical overview. J. Hydrol., 231-232, 4-32.

Doerr, S.H., Shakesby R.A., Walsh R.P.D., 2000. Soil water repellency: its causes, characteristics and hydrogeomorphological significance. Earth Sci. Rev., 51, 33-65.

Ellerbrock, R.H., Gerke, H.H., Bachmann, J., Goebel, M.O., 2005. Composition of organic matter fractions for explaining wettability of three forest soils. Soil Sci. Soc. Am. J., 69, 57-66.

Goebel, M.O., Bachmann, J., Reichstein M., Janssens I.A., Guggenberger G., 2011. Soil water repellency and its implications for organic matter decomposition - Is there a link to extreme climatic events? Global Change Biol., 17, 2640 -2656 .

Goebel, M.O., Bachmann, J., Woche, S.K., 2008. Modified technique to assess the wettability of soil aggregates: comparison with contact angles measured on crushed aggregates and bulk soil. Eur. J. Soil Sci., 59, 1241-1252.

Goebel, M.O., Bachmann, J., Woche, S.K., Fischer, W.R., 2005. Soil wettability, aggregate stability, and the decomposition of soil organic matter. Geoderma, 128, 80-93.

Goebel, M.O., Woche, S.K., Bachmann, J., 2012. Quantitative analysis of liquid penetration kinetics and slaking of aggregates as related to solid-liquid interfacial properties. J. Hydrol., 442, 63-74.

Goebel, M.O., Woche, S.K., Bachmann, J., Lamparter, A., Fischer, W.R., 2007. Significance of wettability-induced changes in microscopic water distribution for soil organic matter decomposition. Soil Sci. Soc. Am. J., 71, 1593-1599.

Hallett, P.D., Bachmann, J., Czachor, H., Urbanek, E., Bin Zhang, Z., 2010. Hydrophobicity of soil. In: Glinski J., Horabik, J. and Lipiec J. (Eds.), Encyclopedia of Agrophysics, Springer, pp. 378-383.

Hallett, P.D., Nunan, N., Douglas, J.T., Young, I.M., 2004. Millimeter-scale spatial variability in soil water sorptivity: Scale, surface elevation, and subcritical repellency effects. Soil Sci. Soc. Am. J., 68, 352-358.

Hallett, P.D., Young, I.M., 1999. Changes to water repellence of soil aggregates caused by substrate-induced microbial activity. Eur. J. Soil Sci., 50, 35-40.

Jaramillo, D.F., Dekker, L.W., Ritsema, C.J., Hendrickx, J.M.H., 2000. Occurrence of soil water repellency in arid and humid climates. J. Hydrol., 231-232, 105-111.

Jarvis, N.J., 2007. A review of non-equilibrium water flow and solute transport in soil macropores: principles, controlling factors and consequences for water quality. Eur. J. Soil Sci., 58, 523-546.

Lamparter, A., Bachmann, J., Deurer, M., Woche, S.K., 2010a. Applicability of ethanol for measuring intrinsic hydraulic properties of sand with various water repellency levels. Vadose Zone J., 9, 445-450.
Lamparter, A., Bachmann, J., Woche, S.K., 2010b. A new technique to determine small scale spatial heterogeneity of contact angles using the sessile drop method. Soil Sci. Soc. Am. J., 74, 2010-2012.

Madsen, M.D., Zvirzdin, D.L., Petersen, S.L., Hopkins, B.G., Roundy, B.A., Chandler, D.G., 2011. Soil water repellency within a burned pinon-juniper woodland: Spatial distribution, severity, and ecohydrologic implications. Soil Sci. Soc. Am. J., 75, 1543-1553.

Moore, D., Kostka, S.J., Boerth, T.J., Franklin, M., Ritsema, C.J., Dekker, L.W., Oostindie, K., Stoof, C., Wesseling, J., 2010. The effect of soil surfactants on soil hydrological behavior, the plant growth environment, irrigation efficiency and water conservation. J. Hydrol. Hydromech., 58, 142-148 .

Moradi, A.B., Carminati, A., Lamparter, A., Woche, S.K., Bachmann, J., Vetterlein, D., Vogel, H.J., Oswald, S.E., 2012. Is the rhizosphere temporarily water repellent? Vadose Zone J., 11, doi: 10.2136/vzj2011.0120.

Muehl, G.J.H., Ruehlmann, J., Goebel, M.O., Bachmann, J., 2012. Application of confocal laser scanning microscopy (CLSM) to visualize the effect of porous media wettability on unsaturated pore water configuration. J. Soils Sediments, $12,75-85$.

Nunan, N., Wu, K., Young, I.M., Crawford, J.W., Ritz, K., 2002. In situ spatial patterns of soil bacterial populations, mapped at multiple scales, in an arable soil. Microb. Ecol., 44, 296-305.

Or, D., Smets, B.F., Wraith, J.M., Dechesne, A., Friedman, S.P., 2007. Physical constraints affecting bacterial habitats and activity in unsaturated porous media - a review. Adv. Water Resour., 30, 1505-1527.

Ramírez-Flores, J.C., Woche, S.K., Bachmann, J., Goebel, M.O., Hallett, P.D., 2008. Comparing capillary rise contact angles of soil aggregates and homogenized soil. Geoderma, 146, 336-343.

Ritsema, C.J., Dekker, L.W., 1996. Water repellency and its role in forming preferred flow paths in soils. Austr. J. Soil Res., 34, 475-487.

Roy, J.L, McGill, W.B., 2002. Assessing soil water repellency using the molarity of ethanol droplet (MED) test. Soil Sci., 167, 83-97.

Tillman, R.W., Scotter, D.R., Wallis, M.G., Clothier, B.E., 1989. Water-repellency and its measurement by using intrinsic sorptivity. Austr. J. Soil Res., 27, 637-644.

Woche, S.K., Goebel, M.O., Kirkham, M.B., Horton, R., van der Ploeg, R.R., Bachmann, J., 2005. Contact angle of soils as affected by depth, texture, and land management. Eur. J. Soil Sci., 56, 239-251.

Young, T., 1805. On the cohesion of fluids. Phil. Trans. R. Soc. Lond., 95, 65-87.

Received 3 October 2012 Accepted 22 November 2012 